\title{
POLY(O-METHOXYANILINE) MODIFIED ELECTRODE FOR DETECTION OF LITHIUM IONS
}

\author{
Cleber Antonio Lindino*, Marcella Casagrande, Andréia Peiter e Caroline Ribeiro \\ Departamento de Química, Universidade Estadual do Oeste do Paraná, Rua da Faculdade, 645, 85903-000 Toledo - PR, Brasil
}

Recebido em 16/2/11; aceito em 12/9/11; publicado na web em 8/11/11

\begin{abstract}
This paper reports the use of an electrode modified with poly (o-methoxyaniline) for detecting lithium ions. These ions are present in drugs used for treating bipolar disorder and that requires periodical monitoring of the concentration of lithium in blood serum. Poly $(o-$ methoxyaniline) was obtained electrochemically by cyclic voltammetry on the surface of a gold electrode. The results showed that the electrode modified with a conducting polymer responded to lithium ions in the concentration range of $1 \times 10^{-5}$ to $1 \times 10^{-4} \mathrm{~mol} \mathrm{~L}^{-1}$. The results also confirmed that the performance of the modified electrode was comparable to that of the standard method (atomic emission spectrophotometry).
\end{abstract}

Keywords: conducting polymers; bipolar disorder; lithium.

\section{INTRODUCTION}

Since its introduction into Psychiatry, lithium salts remain the main drug for the treatment of patients with bipolar disorders given their effectiveness for controlling the manic phase. ${ }^{1,2}$ Many controlled studies have confirmed the effectiveness of lithium salts in prophylaxis of both phases (manic and depressive) of bipolar disorder.

One theory one the metal's mechanism of action holds that it is effective for controlling maniac episodes because it acts by increasing the metabolic activity of brain amines and the reuptake of norepinephrine, responsible for the state of euphoria and excitement, in both patients and healthy subjects. ${ }^{3}$

The therapeutic effect of lithium salts is directly related to the serum concentration of the drug. At concentrations from 0.91 to $1.06 \mathrm{mmol} \mathrm{L}^{-1}$, manic symptoms decrease in around 57 to $73 \%$ of patients. In contrast, at lower concentrations (below $0.43 \mathrm{mmol} \mathrm{L}^{-1}$ ) the manic symptoms decrease in only $39 \%$ of patients. The drug must be monitored constantly, due to pharmacokinetic differences between individuals and to high risk of intoxication. This monitoring must be done using blood serum in order to maintain the proper therapeutically effective concentration of lithium. ${ }^{4,5}$

Several analytical methodologies have been used to achieve tight, fast control of serum concentrations of the drug containing lithium salts. Notable methods include atomic emission and absorption spectrophotometry, ion-selective electrodes, electrophoresis and absorption spectrophotometry. ${ }^{6,7}$ Electrochemical sensors may be a promising approach for implementing a real-time, in situ system offering high precision analysis. The use of conductive polymers underwent rapid expansion in 1990's with the development of $\mathrm{pH}$ sensors, as well as gas, ion-selective and catalytic biosensors. ${ }^{8}$

Intrinsically conducting polymers have attracted the attention of numerous research groups initially, with the synthesis of polyacetylene in the 1970s, given the scientific importance of understanding this new phenomenon as well as their potential for use in technological applications. Such polymers combine the mechanical properties and processability of conventional polymers with electrical, optical and magnetic behaviors, similar to those of metals and inorganic semiconductors. Owing to this characteristic, these materials fall under the category of so-called "Synthetic Metals". ${ }^{8}$ Great advances have been made in recent years in the technological application of these

*e-mail: cleberlindino@yahoo.com.br materials for rechargeable batteries, electronic devices, thermal and chemical sensors, biosensors, smart windows etc. ${ }^{9-12}$

An important point that should be considered when choosing a potentially conducting polymer is the ease with which the system can be oxidized or reduced without causing destabilization of the molecule, thereby giving preference to structures that have conjugated unsaturations (low oxidation potential), i.e. $\pi$ electrons. For this reason, aniline and its derivatives have been extensively studied for their chemical stability, ease of polymerization and doping, besides low cost. ${ }^{8}$

A derivative of aniline polymers is poly( $o$-methoxyaniline) (POMA), which has a methoxy group $\left(-\mathrm{OCH}_{3}\right)$ in the ortho position of the carbon rings, exhibiting physical and chemical properties similar to polyaniline (PANI). POMA can be obtained in different oxidation states: leucoemeraldine, emeraldine and pernigraniline; the emeraldine oxidation state can be found as a base (non electrical conductor) or salt (electrical conductor). ${ }^{13}$ Conversion from emeraldine base to emeraldine salt can be achieved via protonation in acid medium. Thus these oxidation states are also called undoped and doped, respectively. ${ }^{14}$ Figure 1 shows POMA's structure.

a)

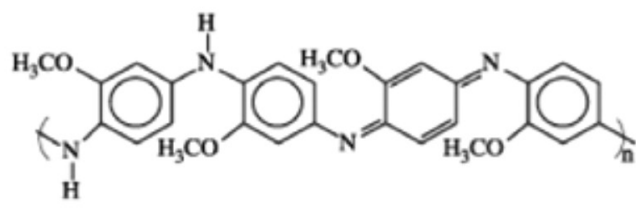

b)

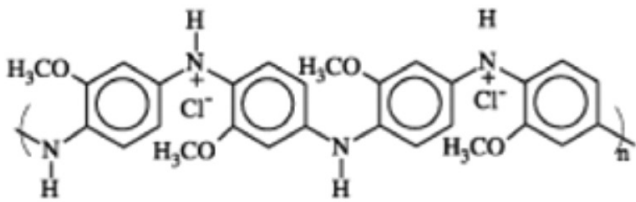

Figure 1. Chemical structure of poly(o-methoxyaniline). a) emeraldine base, b) emeraldine salt ${ }^{15}$

However, literature on POMA modified electrodes and detection of lithium ions is scarce. ${ }^{16-18}$ Previous studies showed that the lithium ion is an important interference in determining the $\mathrm{pH}$ using modified electrodes with poly( $o$-methoxyaniline), due to interaction with the nitrogen of the polymer. ${ }^{19}$ Conductive polymer materials, including poly(o-methoxyaniline), and electrochemical instrumentation, have lead to the construction of microelectrodes with heightened sensitivity 
to macro stimulation, and allowed these devices to be pooled into a single set (microarrays). ${ }^{20,21}$

This paper reports the use of modified electrodes prepared with $\operatorname{poly}(o$-methoxyaniline) for the determination of lithium ions in solution.

\section{EXPERIMENTAL}

$O$-methoxyaniline (Merck) was purified by double distillation under reduced pressure in the presence of zinc powder to remove oxidized impurities. The distillate was stored under refrigeration at $-2.2{ }^{\circ} \mathrm{C}$ in a nitrogen gas atmosphere and protected from light.

All reagents were of analytical grade and the water used for the solutions was purified by distillation and reverse osmosis (ADAMO, water resistivity of $5 \mathrm{M} \Omega \mathrm{cm}$ at $25{ }^{\circ} \mathrm{C}$ ). The gas used for deoxygenation in the voltammetric measurements was $\mathrm{N}_{2}$ (AGA 99.999\%).

The polymer film of $o$-methoxyaniline was obtained on the Au electrode (with a geometric area of $0.18 \mathrm{~cm}^{2}$ ) by cyclic voltammetry with a scan rate of $100 \mathrm{mV} \mathrm{s}^{-1}$ in deoxygenated solution containing $50 \mathrm{mmol} \mathrm{L}^{-1}$ of the monomer and $1.0 \mathrm{~mol} \mathrm{~L}^{-1} \mathrm{HCl}$ as the supporting electrolyte with a scan potential of between 0 and $1.1 \mathrm{~V}$. The reference electrode was a saturated calomel electrode (SCE) and a platinum plate as an auxiliary electrode.

The electrochemical characterization of the polymer film was performed by cyclic voltammetry in a solution of $0.5 \mathrm{~mol} \mathrm{~L}^{-1} \mathrm{HCl}$, at a scan rate of $100 \mathrm{mV} \mathrm{s}^{-1}$ and a scan potential of between 0 and $1 \mathrm{~V} v s$. SCE.

Polymerization and electrochemical response studies were performed in a Microquimica PG-01 potentiostat coupled to a computer.

The potentiometric response measurements were made using a Tecnopon mPA-210 potentiometer with input impedance of $10^{13} \Omega$ and different concentrations of $\mathrm{Li}^{+}$in phosphate buffer at $\mathrm{pH} 5.1$ and an ionic strength of $0.7 \mathrm{~mol} \mathrm{~L}^{-1}$. The reference electrode was a $\mathrm{Ag} / \mathrm{AgCl}$ with an internal solution of saturated $\mathrm{KCl}$.

The flame photometer was used as the reference method (Digimed - 02), with two-point calibration wand minimum $\mathrm{LiCl}$ purity of 99.0\% (Merck) at analytical reagent grade.

The analytical parameters studied were selectivity, analytical curve, accuracy, precision, limit of detection and recovery.

Semiempirical calculations were performed using the ArgusLab 4.0.1 program (free software), AM1, Hartree-Fock SCF. The structures were optimized starting first with the monomer, then dimer, trimer, and the pentamer structure of the polymer, sufficient to designate the whole polymeric molecule. ${ }^{22}$ Subsequently, $\mathrm{Li}^{+}$was placed in different positions within the structure of $\operatorname{poly}(o$-methoxyaniline) and energies were compared in arbitrary units (a.u.). The lithium ion was placed in the positions above, below and in front of the nitrogen molecule in the polymer.

\section{RESULTS AND DISCUSSION}

Figure 2 shows the first cycle of polymerization of $o$-methoxyaniline on the gold electrode.

The oxidation of the monomer on the surface of the gold electrode, forming a cation radical, starts at the potential of $0.9 \mathrm{~V} v s \mathrm{SCE}$ and the anodic current increases exponentially up to the potential of around $1.1 \mathrm{~V}$, at which point reversion of the anodic current.

In the first cycle, after the reversal of potential scan, loops with the anodic reverse scan appear that are higher than those of a direct scan, indicating that the initial oxidation process of the monomer is activated by the modification of the gold electrode surface. This response indicates that a nucleation process occurring on the poly $(o$-methoxyaniline) surface. The modification of this electrode or

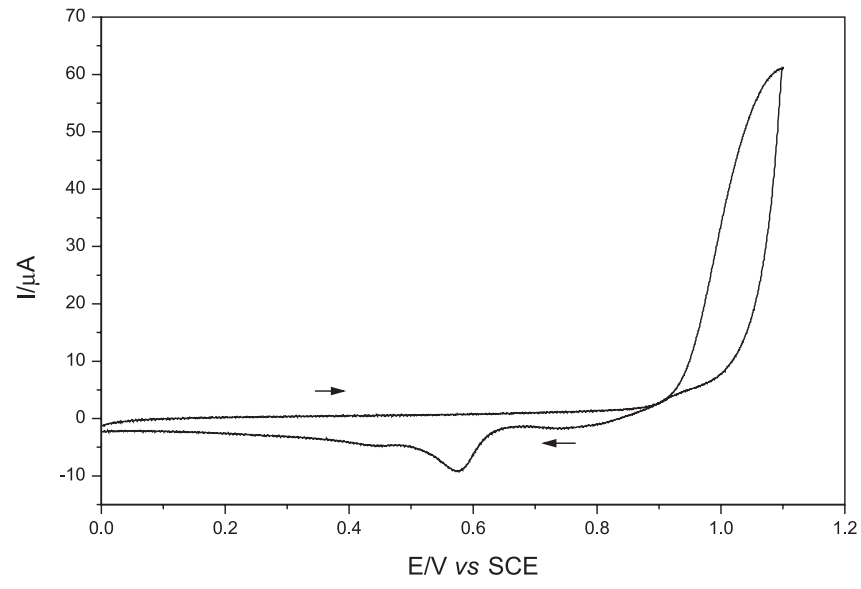

Figure 2. Cyclic voltammogram (first cycle) of polymerization of $50 \mathrm{mmol} \mathrm{L}^{-1}$ o-methoxyaniline in $1.0 \mathrm{~mol} \mathrm{L^{-1 }} \mathrm{HCl}$. Temperature of $25.0{ }^{\circ} \mathrm{C}$. The arrows indicate the direction of potential sweep

the formation of the first polymeric layer involves different processes such as adsorption, nucleation and oligomerization. These processes are crucial steps to the polymerization rate. The reverse scan shows the reduction of the first polymeric layer deposited on the electrode. ${ }^{19}$

In subsequent cycles, the anodic peak observed at more positive potentials gradually decreases, suggesting that the film formed partially blocks the electrode. The process of forming the polymer becomes more complex, with increasing anodic and cathodic currents, indicating the growth of the polymer film. During successive scans, the formation of well-defined anodic and cathodic peaks occurs, which are associated with redox processes taking place at the electrode surface, as shown in Figure 3.

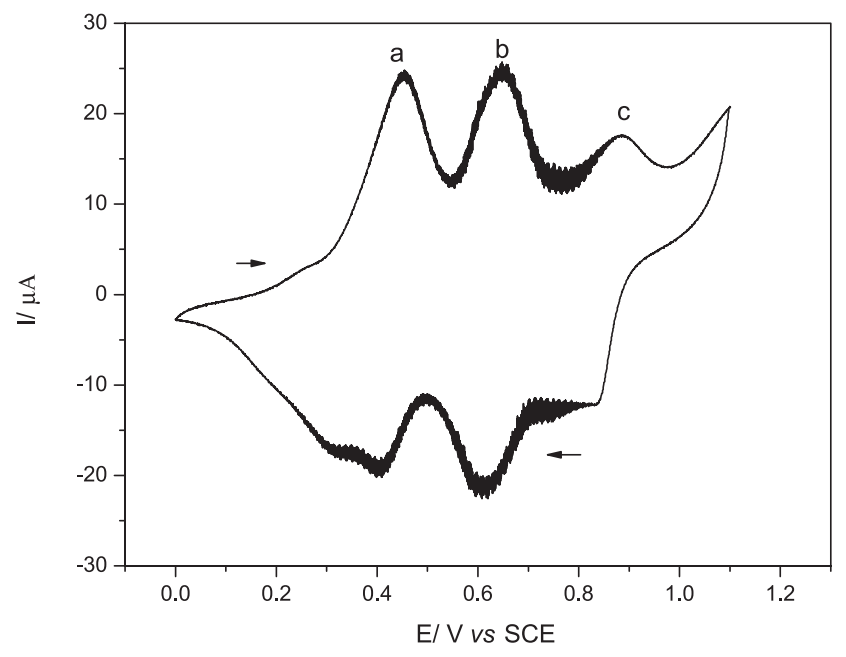

Figure 3. Cyclic voltammogram $\left(65^{\text {th }}\right.$ cycle) of the polymerization of $50 \mathrm{mmol} \mathrm{L} \mathrm{L}^{-1}$ o-methoxyaniline in $1.0 \mathrm{~mol} \mathrm{~L}{ }^{-1} \mathrm{HCl}$. Temperature of $25.0{ }^{\circ} \mathrm{C}$. The arrows indicate the direction of potential sweep

The process of forming radical cations occurs in (a). This process is independent of $\mathrm{pH}$, with no participation of protons. The second peak (b) is attributed to effects of degradation of the film, due to parallel reactions that lead to the formation of soluble intermediates. The peak (c) corresponds to the formation of dication radical and oxidation of the monomer on the polymer, which is catalyzed by the newly formed film. This redox couple indicates that the product formed at this potential and accumulated on the electrode surface, reacts with the oxidized monomer present at the interface and is then 
reduced with the reverse sweep..$^{23}$ This pair of peaks can be attributed to radical dication species, ${ }^{8}$ and this process is dependent on the $\mathrm{pH}$ of the solution. ${ }^{13}$

For the polymerization of $o$-methoxyaniline, all the assumptions made for the polymerization of aniline are accepted. ${ }^{24-26}$ However, the substituent group may cause some effects that change the reaction, for example, changes in the basicity and mobility of the monomer in the reaction medium. Moreover, the presence of the methoxy group sterically prevents polymerization at position 2 in Figure 1, and leads to the formation of more linear products.

The polymerization process was completed when the scan showed that it (the polymerization) attained the potential $0.7 \mathrm{~V}$. This scan avoids overoxidation of the polymer and its degradation, resulting in a green emeraldine polymer form.

The study of poly ( $o$-methoxyaniline) films in $0.5 \mathrm{~mol} \mathrm{~L}^{-1} \mathrm{HCl}$ shows that the voltammograms are characterized by two anodic and three cathodic peaks, indicating electroactive regions with two well-defined reversible electrochemical systems. The voltammogram is similar to that obtained in Figure 3 . The first anodic peak $(0.47 \mathrm{~V})$ is associated with the redox reaction from fully reduced species (leucoemeraldine insulator) to the emeraldine species (conducting) whereas the second anodic peak $(0.65 \mathrm{~V})$ is associated with oxidized products retained in the polymeric matrix. A third peak, if present, would indicate the redox reaction of emeraldine species to pernigraniline species (fully oxidized - conductor). This peak also indicates a degradation process of the polymer by reactions of crosslinking, hydrolysis or splitting of polymeric strings, phenomena not seen in this work. ${ }^{27}$ The cathodic peaks represent the inverse reactions. According to this mechanism, the degree of protonation of polyaniline decreases with increasing oxidation state of the film; for a given oxidation state the protonation increases with increasing acidity of the medium and all polyanilines in base form are insulators, independent of the degree of oxidation. ${ }^{13}$

The modified electrodes were conditioned in a solution containing $\mathrm{Li}^{+}$ions for $24 \mathrm{~h}$ prior to measurements. The potentiometric measurements were performed in triplicate, with a stabilization time of $1 \mathrm{~min}$.

The electrode modified with the conducting polymer showed a linear potentiometric response to $\mathrm{Li}^{+}$in the concentration range between $1.0 \times 10^{-5}$ and $1.0 \times 10^{-4} \mathrm{~mol} \mathrm{~L}^{-1}$, with a correlation coefficient of 0.9992 (Figure 4). Linear response function was $y=445.156+$ 269.364x. Standard deviation and stabilization time increases signifi-

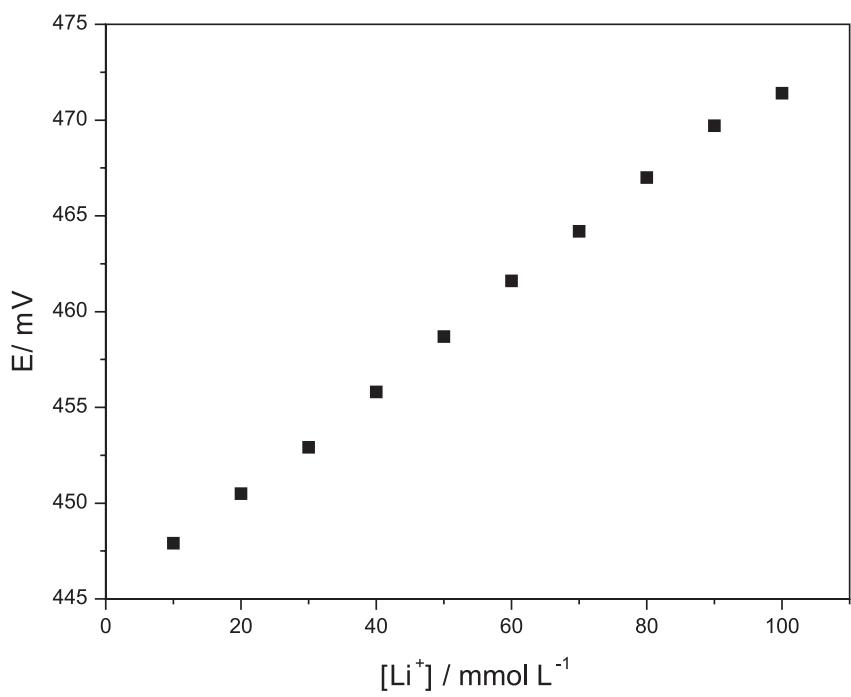

Figure 4. Potentiometric analytical curve of the modified electrode with poly(o-methoxyaniline) to the concentration of lithium ions. Reference electrode: saturated $\mathrm{Ag} / \mathrm{AgCl} / \mathrm{KCl}$. Temperature of $25.0^{\circ} \mathrm{C}$ cantly at lower concentrations of $\mathrm{Li}^{+}$, probably due to delays reaching interaction balance with the conductive polymer.

Effects of adsorption or desorption of $\mathrm{Li}^{+}$ions affect the electronic structure of conducting polymer causing variations in its conductivity. These changes in conductivity result in a change in the potential of the polymer-modified electrode. ${ }^{21}$

An electrode modified with conductive polymers may also obey the capacitor theory. The potential difference is obtained by the difference between the potential on the external interface and internal model in a capacitor. A capacitor electrode can be considered a membrane made of any dielectric or semiconductor material, which can adsorb cations and anions at their active sites. The membrane potential is developed from the two interfaces that store loads on the surface by adsorption in the double layer. The membrane characteristics are given by its permittivity $(\varepsilon)$, area (A), thickness (d), and membrane capacitance $(C)$. When these factors are constant for the same membrane potential is proportional to the load (q) adsorbed on the membrane. If only cations are adsorbed onto the membrane surface $(q-=0)$, results in increased potential with increasing positive charges. ${ }^{28}$ These assumptions may indicate that the conductive polymer does not necessarily show a Nernst response.

The repeatability of the method for nine determinations in sequence yielded a standard deviation (SD) of $1.15 \mathrm{mV}$ and relative standard deviation (RSD) of $0.34 \%$ with $95 \%$ assurance. The repeatability was also studied at three concentration levels in triplicate the results of which are summarized in Table 1.

Table 1. Repeatability on three levels of $\mathrm{Li}^{+}$concentration for the modified electrode poly(o-methoxyaniline)

\begin{tabular}{|c|c|c|}
\hline $\mathrm{Li}^{+}\left(\mathrm{mol} \mathrm{L}^{-1}\right)^{*}$ & SD & $\operatorname{RSD}(\%)$ \\
\hline $1.00 \times 10^{-5}$ & $1.71 \times 10^{-7}$ & 1.71 \\
\hline $5.00 \times 10^{-5}$ & $2.10 \times 10^{-7}$ & 0.42 \\
\hline $1.00 \times 10^{-4}$ & $1.00 \times 10^{-8}$ & 0.01 \\
\hline
\end{tabular}

*Triplicate

The accuracy of potentiometric measurements was determined based on the values obtained by recovery (Table 2) where this procedure was performed in triplicate for four concentrations from the calibration curve.

Table 2. Results of the recovery studies

\begin{tabular}{cccc}
\hline Measure $^{1}$ & Average recovery $(\%)$ & SD & RSD $(\%)$ \\
\hline 1 & 100.4 & 0.2424 & 0.240 \\
2 & 100.3 & 0.5094 & 0.510 \\
3 & 100.2 & 0.2040 & 0.200 \\
4 & 98.40 & 1.602 & 1.630 \\
\hline
\end{tabular}

${ }^{1}$ Triplicate

The incluir of detection (LD) of the modified electrode was $4.12 \times 10^{-6} \mathrm{~mol} \mathrm{~L}^{-1}$ calculated using 3.3 times the ratio of standard deviation of the response and the slope of calibration. This value of LD can be compared with literature values in detection systems using optode $^{29}$ (LD of $\left.1.4 \times 10^{-4} \mathrm{~mol} \mathrm{~L}^{-1}\right), \mathrm{LiFePO}_{4}{ }^{30}$ (LD of $10 \times 10^{-4} \mathrm{~mol}$ $\left.\mathrm{L}^{-1}\right)$, flow-injection analysis ${ }^{31}\left(\mathrm{LD}\right.$ of $\left.80 \times 10^{-6} \mathrm{~mol} \mathrm{~L}^{-1}\right)$ and laser-based semiconductor ( $\mathrm{LD}$ of $\left.3 \times 10^{-6} \mathrm{~mol} \mathrm{~L}^{-1}\right) .{ }^{32}$

The coefficient of selectivity was determined by the "matched potential" method. ${ }^{33,34}$ The values found for the interfering $\mathrm{Na}^{+}$and $\mathrm{K}^{+}$yielded $\mathrm{K}^{\text {pot }}$ values of 0.099 and 0.082 , respectively, indicating that it did not significantly change the potential values measured for 
the lithium ion. Changes in $\mathrm{pH}$ of the buffer caused no change in the value of potential measured relative to the concentration of lithium ions, with the potential remaining constant at different concentrations of $\mathrm{H}_{3} \mathrm{O}^{+}$.

The potentiometric response of the modified electrode showed a tendencys to decline with time, probably due to the insertion of lithium ions into the polymer structure in a strong interaction with the amino groups of poly $(o$-methoxyaniline $)$, saturating the active sites of exchange. Alkali cations are inserted into the polymer film, modifying the redox state of the poly (o-methoxyaniline) and consequently its electrochemical response. The poly (o-methoxyaniline) film was initially bright green, changing to dark blue when immersed in solutions containing lithium for long periods. Based on these observations, semi-empirical calculations were made, giving the energies of the structures with and without $\mathrm{Li}^{+}$ions (Table 3).

Table 3. Energies of polymeric structures with and without $\mathrm{Li}^{+}$ions

\begin{tabular}{cccc}
\hline $\begin{array}{c}\text { Polymer } \\
\text { structure }\end{array}$ & $\begin{array}{c}\text { Distance } \\
\text { between } \mathrm{Li}^{+} \\
\text {and } \mathrm{N}(\AA)\end{array}$ & $\begin{array}{c}\text { Distance } \\
\text { between } \mathrm{Li}^{+} \\
\text {and } \mathrm{O}(\AA)\end{array}$ & $\begin{array}{c}\text { Energy } \\
(\text { a.u. })\end{array}$ \\
\hline Without $\mathrm{Li}^{+}$ & ---- & ---- & -10.3150 \\
${ }^{\mathrm{a}} \mathrm{Li}^{+}$ & 3.13 & 2.96 & -12.6740 \\
${ }^{\mathrm{b}} \mathrm{Li}^{+}$ & 3.64 & 2.76 & -14.1002 \\
${ }^{\mathrm{c}} \mathrm{Li}^{+}$ & 3.62 & 3.53 & -14.1050 \\
\hline
\end{tabular}

an front of nitrogen; below the nitrogen; ${ }^{\mathrm{c}}$ above the nitrogen

The polymer was found to be more stable when the lithium ion was incorporated into its structure. Hence, it follows that $\mathrm{Li}^{+}$acts as a pseudo-dopant in imine sites of poly(o-methoxyaniline), since in addition to stabilizing the structure, it increases the conductivity of the polymer. ${ }^{35,36}$ This effect of high occupancy of $\mathrm{Li}^{+}$ions at the sites of reduction alters the response of the redox polymer as well as the process of insertion and deinsertion of solvated $\mathrm{Li}^{+}$ions. ${ }^{37}$

Structural and electronic properties of pristine and lithium-intercalated, phenyl-capped aniline dimers as a model for the lithium-polyaniline system have been studied by photoelectron spectroscopy and quantum chemical calculations. ${ }^{38}$ It was found that the electronic structure of reduced and oxidized forms of oligoanilines is only weakly affected by isomerism. Upon intercalation, charge transfer from the Li-atoms is remarkable and highly localized at $\mathrm{N}$-atomic sites, where configurations in which both $\mathrm{N}$ atoms of the dimers are bound to $\mathrm{Li}$ atoms are energetically favored. The introduction of lithium ions into the polymer structure causeds a strong interaction with nitrogen sites, indicating that the equilibrium exchange is not favored, limiting the potentiometric response of the modified electrode.

The modified electrodes, after a period of $24 \mathrm{~h}$ in buffer $\mathrm{pH} 5.1$, returned to the initial potentiometric response, showing that the insertion of $\mathrm{Li}^{+}$into the structure affects the electrochemical properties of poly(o-methoxyaniline).

The accuracy of the electrode modified with poly(o-methoxyaniline) was evaluated by comparing the results with those obtained by atomic emission spectrophotometry, with the flame method (reference). The results of this comparison are given in Table 4 .

The results show that the performance of the modified electrode was comparable to the standard method (atomic emission spectrophotometry).

\section{CONCLUSION}

The results indicated that the potentiometric electrode modified with poly (o-methoxyaniline) can be used for the determination of $\mathrm{Li}^{+}$
Table 4. Accuracy of the proposed (POMA) and flame emission method in the determination of $\mathrm{Li}^{+}$ions $\left(\mathrm{mol} \mathrm{L}^{-1}\right)$

\begin{tabular}{cccc}
\hline $\begin{array}{c}\text { Nominal } \\
\text { concentration }\end{array}$ & $\begin{array}{c}\text { Reference } \\
\text { concentration }^{1}\end{array}$ & $\begin{array}{c}\text { POMA } \\
\text { electrode } \\
\text { concentration }^{1}\end{array}$ & $\begin{array}{c}\text { Relative } \\
\text { error \% }\end{array}$ \\
\hline $2.00 \times 10^{-5}$ & $1.88 \times 10^{-5}$ & $1.93 \times 10^{-5}$ & 2.66 \\
$5.00 \times 10^{-5}$ & $4.70 \times 10^{-5}$ & $4.79 \times 10^{-5}$ & 1.91 \\
$8.00 \times 10^{-5}$ & $7.52 \times 10^{-5}$ & $7.65 \times 10^{-5}$ & 1.73 \\
\hline
\end{tabular}

${ }^{1}$ Triplicate; ${ }^{2}$ between the reference method and the proposed method.

ions in solution for at concentration range of between $1.0 \times 10^{-5}$ and $1.0 \times 10^{-4} \mathrm{~mol} \mathrm{~L}^{-1}$. Data shows that the insertion of $\mathrm{Li}^{+}$into the structure affects the electrochemical properties of poly (o-methoxyaniline) and sensor response. The ease of polymerization of o-methoxyaniline, and its response to lithium ions, enable the construction of microsensors for catheters adapted for in situ determination of this ion.

To ressolve the problem of insertion of lithium ions within the polymer structure, the use of flow injection analysis has been suggested, in order to reduce the contact time between the polymer and lithium ions given that the analysis process is dynamic.

\section{REFERENCES}

1. Shorter, E.; Bipolar disorders 2009, 11, 4.

2. Grof, P.; Neuropsychobiology 2010, 62, 8.

3. Leal, A. C. M.; Fernandes, A. S. G.; Biologias 2005, 4.

4. Grof, P.; Muller-Oerlinghausen, B.; Bipolar disorders 2009, 11, 10.

5. Pascali, J. P.; Sorio, D.; Bortolotti, F.; Tagliaro, F.; Anal. Bioanal. Chem. 2010, 396, 2543.

6. Gruson, D.; Lallali, K.; Conti, M.; Legrand, A.; Gruson, A.; Wallemacq, P. E.; Trace elements and electrolytes 2007, 24, 6.

7. Floris, A.; Staal, S.; Lenk, S.; Staijen, E.; Kohlheyer, D.; Eijkel, J.; van den Berg, A.; Lab-on-a-chip 2010, 10, 1799.

8. Mattoso, L. H. C.; Quim. Nova 1996, 19, 388.

9. Peron, J.; Shi, Z.Q.; Holdcroft, S.; Energy and Environmental Science 2011, 4, 1575 .

10. Cosnier, S.; Holzinger, M.; Chem. Soc. Rev. 2011, 40, 2146.

11. AlSalhi, M. S.; Alam, J.; Dass, L. A.; Raja, M.; Int. J. Molecular Sci. 2011, 12, 2036.

12. Katz, H. E.; Searson, P. C.; Poehler, T. O.; J. Mater. Res. 2010, 25, 1561.

13. Koval'chuk, E. P.; Stratan, N. V.; Reshetnyak, O. V.; Blazejowski, J.; Whittingham, M. S.; Solid State Ionics 2001, 141-142, 217.

14. Mattoso, L. H. C.; Bulhões, L. O. S.; Synth. Met. 1992, 52, 171.

15. Eiras, C.; Passos, I. N. G.; Brito, A. C. F.; Santos Jr., J. R.; Zucolotto, V.; Oliveira Jr., O. N.; Kitagawa, I. L.; Constantino, C. J. L.; Cunha, H. N.; Quim. Nova 2007, 30, 1158.

16. Taddia, M.; Mattioli, M.; Inorg. Chim. Acta 2007, 360, 1226.

17. Mu, X.; Jain, C.; US pat. 6,508,921 2003.

18. Lindfors, T.; Sjöberg, P.; Anal. Chim. Acta 1999, 385, 163.

19. Lindino, C. A.; Bulhões, L. O. S.; Anal. Chim. Acta 1996, 334, 317.

20. Imisides, M. D.; John, R.; Wallace, G. G.; Chemtech. 1996, 19.

21. Rover Jr., L.; Oliveira Neto, G.; Kubota, L. T.; Quim. Nova 1997, 20, 519.

22. Vaschetto, M. E.; Retamal, B. A.; Contreras, M. L.; Zagal, J. H.; Bulhões, L. O. S.; Struct. Chem. 1995, 6, 129.

23. Lindino, C. A.; Dissertação de Mestrado, Universidade Federal de São Carlos, Brasil, 1997.

24. Gonçalves, D.; Matvienko, B.; Bulhões, L. O. S.; J. Electroanal. Chem. 1994, 371, 267.

25. Manohar, S. K.; MacDiamird, A. G.; Epstein, A. J.; Synth. Met. 1991, 41,711 . 
26. Gospodinova, N.; Terlemezyan, L.; Mokreva, P.; Kossev, K.; Polymer 1993, 34, 2434.

27. Geniès, E. M.; Penneau, J. F.; Lapkowski, M.; Boyle, A.; J. Electroanal. Chem. 1989, 269, 63.

28. Fernandes, J. C. B.; Kubota, L. T.; Oliveira Neto, G.; Quim. Nova 2001, $24,120$.

29. Albero, M. I.; Ortuno, J. A.; Garcia, M. S.; Cuartero, M.; Alcaraz, M. C.; Sens. Actuators, B 2010, 145, 133.

30. Sauvage, F.; Tarascon, J. M.; Baudrin, E.; Anal. Chim. Acta 2008, 622 , 163.

31. Coldur, F.; Andac, M.; Isildak, I.; J. Solid State Electrochem. 2010, 14, 2241.
32. Ermolenko, Y.; Yoshinobu, T.; Mourzina, Y.; Furuichi, K.; Levichev, S.; Vlasov, Y.; Schöning, M. J.; Iwasaki, H.; Anal. Chim. Acta 2002, 459, 1.

33. Gadzekpo, V. P. Y.; Christian, G.; Anal. Chim. Acta 1984, 164, 279.

34. Umezawa, Y.; Umezawa, K.; Sato, H.; Pure Appl. Chem. 1995, 67, 507.

35. Gonçalves, D.; Mattoso, L. H. C.; Bulhões, L. O. S.; Electrochim. Acta 1994, 39, 2271.

36. Sengupta, P. P.; Kar, P.; Adhikari, B.; React. Funct. Polym. 2008, 68, 1103.

37. Wang, G.; Yang, Z.; Xingwei, L.; Chunzhong, L.; Carbon 2005, 43, 2564.

38. Kuritka, I.; Negri, F.; Brancolini, G.; Suess, C.; Salaneck, W. R.; Friedlein, R.; J. Phys. Chem. A 2006, 110, 19023. 